\title{
Conus Medullaris Levels on Ultrasonography in Term Newborns : Normal Levels and Dermatological Findings
}

\author{
Kiyasettin Asil, M.D., ${ }^{1}$ Mahizer Yaldiz, M.D. ${ }^{2}$ \\ Departmants of Radiology, Dermatology, Sakarya University Training and Research Hospital, Sakarya, Turkey
}

Objective : Ultrasonography (US) is the most non-invasive, safe, and, especially in the period of infancy, best method for visualizing and examining the spinal cord. Furthermore, US is the primary work-up for development of the spinal canal, and for follow-up on issues relating to subcutaneous tissues, bone development, and the spinal cord. Conus medullaris terminates at the second lumbar vertebra, according to a consensus in the literature.

Methods : Healthy children under the age of 6 months who were admitted to the radiology clinic for routine USG follow-ups between the dates of March 2012 to December 2014 were included in this study.

Results : Our study includes data from 1125 lumbosacral ultrasounds. The terminal point of the conus level of the attended infants, superior, middle part, inferior of the vertebrae L1, $\mathrm{L} 2$, and $\mathrm{L} 3$. Furthermore, the termination of the discal distance ratio did not differ significantly between genders.

Conclusion : Therefore, according to our results, gender is not an influencing factor in the termination of the spinal cord. Based on the study we performed, as well as the previous literature, in infants without a recognized spinal pathology, the spinal cord is detected below the vertebra L3.

Key Words : Ultrasonography · Term birth · Conus medullaris.

\section{INTRODUCTION}

Ultrasonography (US) is the most non-invasive, safe, and, especially in the period of infancy, best method for visualizing and examining the spinal cord. Furthermore, US is the primary work-up for development of the spinal canal, and for follow-up on issues relating to subcutaneous tissues, bone development, and the spinal cord ${ }^{6,10,11)}$. Conus Medullaris (CM) terminates at the second lumbar (L) vertebra, according to a consensus in the literature.
In the embryological period, the medulla spinalis is the same length as the spinal canal, and along with the development it ascends cranially. The exact time of this ascent has not been determined ${ }^{11}$. Regarding diagnosis, $\mathrm{CM}$ is determined to be pathological when it is located in the lower lumbar region, and is called low or tethered spinal cord at that time. It presents as sphincter dysfunctions and neurological deficits of the lower extremities.

In preterm infants, because the ascent of the conus has not been completed, it can be encountered at lower levels. This sit-

- Received : December 7, 2016 •Revised : March 7, 2017 •Accepted : March 8, 2017

- Address for reprints : Mahizer Yaldiz, M.D.

Department of Dermatology, Sakarya Training and Research Hospital, Adnan Menderes Caddesi Sağlık Sokak No: 195 Adapazarı, Sakarya 54100, Turkey Tel : +90-505-357-22-22, Fax : +90-264-275-91-92, E-mail : drcanyaldiz@yahoo.com

This is an Open Access article distributed under the terms of the Creative Commons Attribution Non-Commercial License (http://creativecommons.org/licenses/by-nc/4.0) which permits unrestricted non-commercial use, distribution, and reproduction in any medium, provided the original work is properly cited. 
uation can be misinterpreted by clinicians, ${ }^{6,11,15,16)}$. This study was carried out on infants under six months of age without any spinal pathology in order to determine the conus level of the population and the frequency of coexisting dermatological findings.
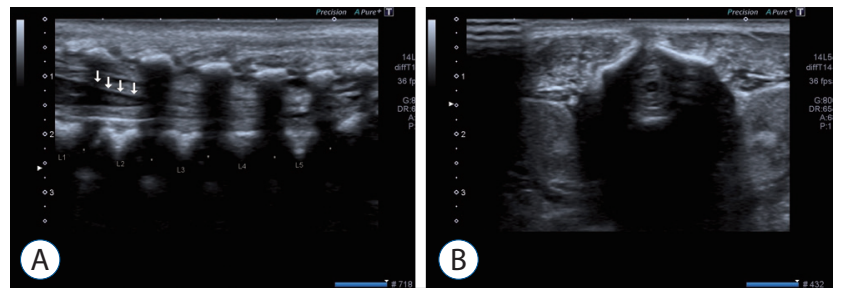

Fig. 1. A : Sonographical images of spinal cord in axial planes in a term infant. White arrows pointed to conus medullaris. B : Sonographical images of spinal cord in Sagittal planes in a term infant.

\section{MATERIALS AND METHODS}

Healthy children under 6 months of age who were admitted to the radiology clinic for routine US follow-ups between the dates of March 2012 to December 2014 were included in this study; in total, 672 term girls and 453 term boys were involved. Our study includes infants until age of 6 months, as there are delays in admitting to hospital for screening in families who have an infant without neurological smptoms other than simple skin lesions and ossification occuring after the 6 th month reduces diagnostic value of the evaluation, with the neonatal period being more significant. Those determined to be preterm infants according to their gestational ages and infants with spinal pathologies detected on US, as well as infants with congenital malformations, were excluded. As ultrasonog-

Table 1. Distribution of conus levels by genders and months

\begin{tabular}{|c|c|c|c|c|c|c|c|c|c|c|c|}
\hline Gender & Months & L1s & L1 & L1i & L1-L2 & L2s & L2 & L2i & L2-L3 & L3s & Total \\
\hline \multicolumn{12}{|l|}{ Male } \\
\hline & 1 & 0 & 0 & 0 & $8(7.1)$ & $26(23.0)$ & $24(21.2)$ & 25 (22.1) & 17 (15.0) & 13 (11.5) & 113 \\
\hline & 2 & 0 & $2(2.0)$ & $5(4.9)$ & $13(12.7)$ & 21 (20.6) & 20 (19.6) & $23(22.5)$ & $10(9.8)$ & $8(7.8)$ & 102 \\
\hline & 3 & $2(2.4)$ & $3(3.7)$ & $11(13.4)$ & $12(14.6)$ & $19(23.2)$ & 17 (20.7) & $7(8.5)$ & $9(11.0)$ & $2(2.4)$ & 82 \\
\hline & 4 & $4(5.4)$ & $4(5.4)$ & $13(17.6)$ & $16(21.6)$ & 15 (20.3) & 14 (18.9) & $4(5.4)$ & $4(5.4)$ & 0 & 74 \\
\hline & 5 & $4(9.3)$ & $4(9.3)$ & 8 (18.6) & $12(27.9)$ & $7(16.3)$ & $6(14.0)$ & $2(4.7)$ & 0 & 0 & 43 \\
\hline & 6 & $5(12.8)$ & $5(12.8)$ & $8(20.5)$ & $11(28.2)$ & $5(12.8)$ & $5(12.8)$ & 0 & 0 & 0 & 39 \\
\hline & Total & 15 & 18 & 45 & 72 & 93 & 86 & 61 & 40 & 22 & 453 \\
\hline \multicolumn{12}{|l|}{ Female } \\
\hline & 1 & 0 & 0 & $4(1.9)$ & $18(8.5)$ & $47(22.1)$ & $41(19.2)$ & 35 (16.4) & 40 (18.8) & $28(31.1)$ & 213 \\
\hline & 2 & 0 & 0 & $7(4.9)$ & 15 (10.4) & $38(26.4)$ & $32(22.2)$ & $24(16.7)$ & $16(11.1)$ & $12(8.3)$ & 144 \\
\hline & 3 & $2(2.3)$ & $2(2.3)$ & $9(10.5)$ & $17(19.8)$ & $17(19.8)$ & 16 (18.6) & 15 (17.4) & $3(3.5)$ & $5(5.8)$ & 86 \\
\hline & 4 & $3(3.3)$ & $4(4.4)$ & $19(21.1)$ & 31 (34.4) & $14(15.6)$ & $11(12.2)$ & $6(6.7)$ & $2(2.2)$ & 0 & 90 \\
\hline & 5 & $6(7.8)$ & $5(6.5)$ & 16 (20.8) & 22 (28.6) & $16(20.8)$ & $8(10.4)$ & $4(5.2)$ & 0 & 0 & 77 \\
\hline & 6 & 8 (12.9) & $5(8.1)$ & 12 (19.4) & 17 (27.4) & 12 (19.4) & $8(12.9)$ & 0 & 0 & 0 & 62 \\
\hline & Total & 19 & 16 & 67 & 120 & 144 & 116 & 84 & 61 & 45 & 672 \\
\hline \multicolumn{12}{|l|}{ Total } \\
\hline & 1 & 0 & 0 & $4(1.2)$ & $26(8.0)$ & 73 (22.4) & 65 (19.9) & $60(18.4)$ & $57(17.5)$ & 41 (12.6) & 326 \\
\hline & 2 & 0 & $2(0.8)$ & $12(4.9)$ & 28 (11.4) & $59(24.0)$ & $52(21.1)$ & 47 (19.1) & $26(10.6)$ & $20(8.1)$ & 246 \\
\hline & 3 & $4(2.4)$ & $5(3.0)$ & $20(11.9)$ & $29(17.3)$ & 36 (21.4) & 33 (19.6) & $22(13.1)$ & $12(7.1)$ & $7(4.2)$ & 168 \\
\hline & 4 & $7(4.3)$ & $8(4.9)$ & 32 (19.5) & 47 (28.7) & 29 (17.7) & $25(15.2)$ & $10(6.1)$ & $6(3.7)$ & 0 & 164 \\
\hline & 5 & $10(8.3)$ & $9(7.5)$ & $24(20.0)$ & $34(28.3)$ & 23 (19.2) & 14 (11.7) & $6(5.0)$ & 0 & 0 & 120 \\
\hline & 6 & 13 (12.9) & $10(9.9)$ & $20(19.8)$ & $28(27.7)$ & 17 (16.8) & $13(12.9)$ & 0 & 0 & 0 & 101 \\
\hline & Total & 34 & 34 & 112 & 192 & 237 & 202 & 145 & 101 & 68 & 1125 \\
\hline
\end{tabular}

Values are presented as number (\%). s : superior, i : inferior 
raphy cannot be performed in cases with meningocele or meningomyelocele that would require surgery, they were not included in our study. Participation required examination by pediatricians and dermatological consultations. By combining all data, the frequencies of ultrasonographic conus levels and dermatological lesions were investigated.

We used the Aplio 400 brand Toshiba (Toshiba Medical Systems, Tokyo, Japan) ultrasound device in this study. The infants were gently placed in the prone position for examination. During investigation, the lumbosacral distal junction was accepted as the first apparent angulation level, and according to this, vertebra L5 was determined and the spinal conus level was defined by counting the discal distances. Following this, vertebral bodies were identified at each discal level and classified as superior and inferior endplate and midvertebral body (Fig. 1). The level to which the spinal conus was closest was determined to be the conus termination level.

Table 2. Evaluation of conus levels by genders

\begin{tabular}{lccc}
\hline & Male $(\mathbf{n = 4 5 3 )}$ & Female $(\mathbf{n = 6 7 2 )}$ & $\boldsymbol{p}$-value \\
\hline L1s & $15(3.3)$ & $19(2.8)$ & $0.774^{*}$ \\
L1 & $18(4.0)$ & $16(2.4)$ & $0.176^{*}$ \\
\hline L1i & $45(9.9)$ & $67(10.0)$ & $0.984^{\dagger}$ \\
L1-L2 & $72(15.9)$ & $120(17.9)$ & $0.391^{\dagger}$ \\
\hline L2s & $93(20.5)$ & $144(21.4)$ & $0.717^{\dagger}$ \\
L2 & $86(19.0)$ & $116(17.3)$ & $0.460^{\dagger}$ \\
\hline L2i & $61(13.5)$ & $84(12.5)$ & $0.653^{\dagger}$ \\
L2-L3 & $40(8.8)$ & $61(9.1)$ & $0.887^{\dagger}$ \\
\hline L3s & $23(5.1)$ & $45(6.7)$ & $0.264^{\dagger}$ \\
\hline
\end{tabular}

Values are presented as number (\%). *Yates' continuity correction test. ${ }^{\dagger}$ Pearson chi-square test. s: superior, i : inferior

\section{RESULTS}

Our study included data from 1125 lumbosacral ultrasounds. At the terminal point of the c onus level of the infants' superior, middle, and inferior parts of vertebrae L1, L2, and L3, the termination of the discal distance ratios do not differ significantly between genders ( $p>0.05$ ) (Tables 1-3, Figs. 2 and 3).

During the study, a total of 316 (28\%) infants with skin lesions on their midlines were reported. The dermatological lesions encountered in these children were as follows : Mongolian spot was encountered in 171 children (15.2\%), 92 boys and 79 girls; salmon patches were encountered in 61 children (5.42\%), 10 boys and 51 girls; sacral dimple was encountered in 43 children (3.73\%), 23 boys and 20 girls; pilonidal sinus was encountered in 27 children (2.4\%), 15 boys and 12 girls; hair development in the lumbosacral region was encountered in 15 children (1.24\%), five boys and 10 girls. Both hair development in the lumbosacral region and sacral dimple were present in only one girl (0.08\%). The dermatological findings of the infants involved do not differ significantly with the conus level ( $p>0.05)$ (Fig. 4).

\section{Statistical analyses}

The NCSS 2007 (NCSS, LLC company, Kaysville, UT, USA) program was used for the statistical analyses conducted in this study. During the examination of data, complementary statistical methods (frequency, ratio) were used. For comparison of the qualitative data, the Pearson chi-squared test and Yates' continuity correction test were used. Significance was estimated at levels $p<0.01$ and $p>0.05$.

\section{DISCUSSION}

Methods such as computed tomography and magnetic resonance imaging can be used for follow-ups of spinal cord in period of infancy. These methods can be quite successful, but

Table 3. The mean levels of conus medullaris in all cases

\begin{tabular}{lcccccccccc}
\hline & L1s & L1 & L1i & L1-L2 & L2s & L2 & L2i & L2-L3 & L3s \\
\hline Mean CM levels & 5.67 & 5.67 & 18.67 & 32.00 & 39.50 & 33.67 & 24.17 & 16.83 & 11.33 \\
2xSD & 10.634 & 8.066 & 19.376 & 15.646 & 43.85 & 42.022 & 48.372 & 43.862 & 32.976 \\
\hline
\end{tabular}

$\mathrm{s}$ : superior, i : inferior, CM : conus medullaris, SD : standard deviation 
each also entails significant drawbacks. For instance, computed tomography emits radiation, and anesthesia is required in order for the results of magnetic resonance imaging work-ups to be optimal, at a high cost. In contrast, the fact that USG is non-invasive, easily accessible, radiation-free, and cost-efficient make it the best all-around method, even though it is user-dependent ${ }^{11)}$.

The life of an embryo proceeds through several developmental stages. Embryos are created by the differentiation of three germ layers between the 4th and 8th weeks. On the 17th and 18 th days, the neural plate develops. On the 28th day, the neural plate closes and the spinal canal develops. After neurulation is completed, the tail bud begins to regress gradually ${ }^{1,9,15-17)}$. Any defect occurring in this period of time will lead to difficulties later in the child's development.

Wilson and Prince ${ }^{18)}$ followed 184 children between 0-20 with magnetic resonance imaging. According to this study,

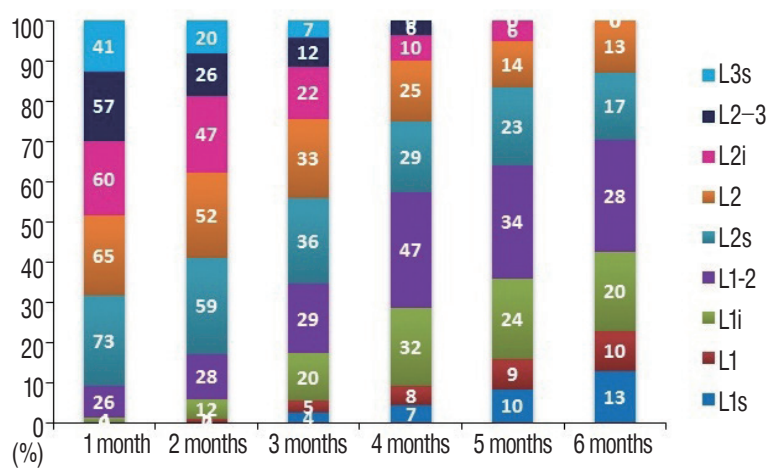

Fig. 2. Distribution of regions where conus levels were determined, by months. $\mathrm{s}$ : superior, $\mathrm{i}$ : inferior.

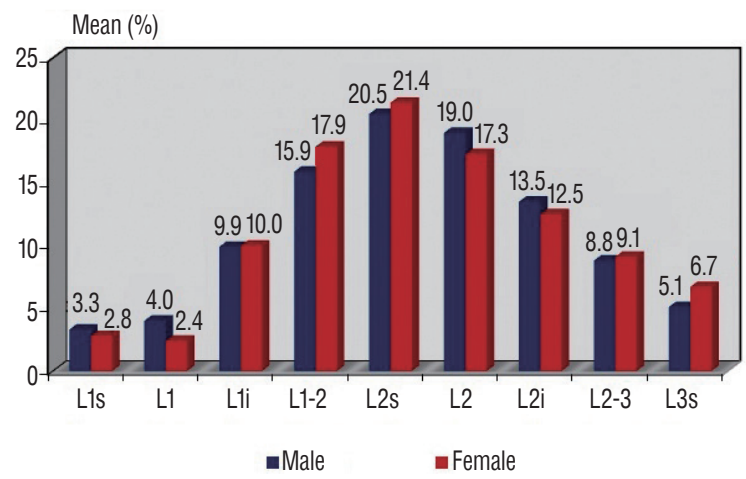

Fig. 3. Distribution of regions where conus levels were determined, by genders. $s$ : superior, $\mathrm{i}$ : inferior.
CM was observed between T12-L3. In another group of patients aged 0-24 months, it was observed between L1-L2 levels. In contrast, Hill and Gibson ${ }^{6}$ reported CM to be located between L1-L2 most frequently in a 105-patient neonatal case study performed using $\mathrm{US}^{18)}$, and Sahin et al. ${ }^{11)}$ reported it between L1-L2 in an examination of 105 premature and term infants, also performed using US. Further, Arthurs et al. ${ }^{1)}$ reported that it was at L4-L5 and above in $84.2 \%$ and at L3 and above in $22.8 \%$ of the fetuses examined, all in the 20th gestational week. Other studies on the subject, such as Perlitz et al. ${ }^{9}$, reported it at the L2-L3 vertebral space and vertebra L3 in 93\%

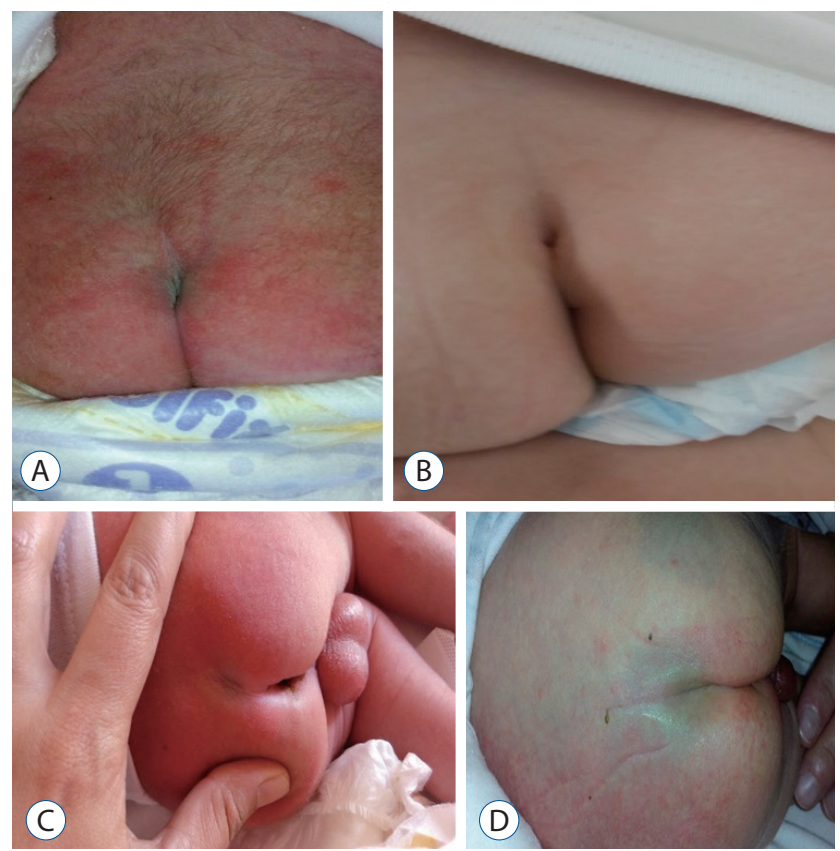

Fig. 4. A : Dermatological samples from involved cases. Hair development in lumbar region. B : Dermatological samples from involved cases. Pilonidal sinus. C : Dermatological samples from involved cases. Sacral dimple. D : Dermatological samples from involved cases. Mongolian spot.

Table 4. Termination levels of spinal coni by vertebrae, regardless of gender, in all cases

\begin{tabular}{lcccc}
\hline Months & L1 & L2 & L3 & Total \\
\hline 6 & 71 & 30 & 0 & 101 \\
\hline 5 & 77 & 43 & 0 & 120 \\
\hline 4 & 94 & 70 & 0 & 164 \\
3 & 58 & 103 & 7 & 168 \\
\hline 2 & 42 & 184 & 20 & 246 \\
1 & 30 & 255 & 41 & 326 \\
\hline Total & 372 & 685 & 68 & 1125 \\
\hline
\end{tabular}


of 110 fetuses studied at the 20-24th gestational weeks. Relatedly, Zalel et al. ${ }^{20)}$ evaluated fetuses at the 10th and 40th gestational weeks using US; in all of the fetuses at the 13-18th gestational weeks, CM was detected at L5 and the sacrum, and in all of the term fetuses it was at L2 and above. In their study featuring 1273 infants, Rozzelle et al. ${ }^{10)}(0-100$ days) used US to locate CM between T12-L4, mostly between vertebrae L1-L2; 10.4\% of it was measured at the L2-L3 space. In our study, in the period of the first 6 months, CM was observed at L1-L2 (192 children), most commonly at the superior (237 children) or middle parts of the vertebra L2 (202 children), and least commonly at the superior (34 children) and middle parts (34 children) of the vertebra (Table 1). Therefore, the results of our study are concordant with those of Wilson and Prince ${ }^{18}$, Sahin et al. ${ }^{11)}$, and Hill and Gibson ${ }^{6}$.

It has been demonstrated in some articles in the literature that Sahin et al. ${ }^{11)}$ and Vettivel ${ }^{14)}$ did not find conus level to be related to gender. Our study was in agreement with this, finding no relationship between gender and the conus level of participants. In the literature, CM is accepted as pathological when it is below vertebra L3. In this case, the cause of symptoms such as neurological deficits in the lower extremities or bladder dysfunctions was often the tethered cord syndrome ${ }^{199}$. In our study, there were no conus medullaris observed terminating below vertebra L3. Although we did not recognize a case with conus terminating at the level of vertebra L3; when we assessed a total of 61 cases with conus terminating at upper plateau of the vertebra L3 within initial 3 months, in examinations of infants included in our screening there was no neurological sign or symptom, initial measurements of the cases included in the screening were used as a basis and no data regarding cases with prolonged follow-up could not be obtained and we may suggest that termination of conus at upper plateau of the vertebra L3, which was found to be normal in our study, would not always be pathological, as the cases were not followed-up routinely. Furthermore, termination at this level is not observed in our cases since the age of 4 months and as it is outlined in Table 4 (the table requested), we are in thought of that termination level of conus hightens gradually with the age of the case.

In newborns, midline skin lesions are commonly encountered. Mongolian spot, salmon patch (bite mark of stork on the neck), sacral dimple, hair development in the lumbosacral region, pilonidal sinus, sacral skin tag, subcutaneous mass, and aplasia cutis are all dermatological findings that can be observed. Apart from Mongolian spot and salmon patch, these lesions can accompany spinal dysraphism ${ }^{2-5,12)}$. In a study conducted by Henriques et al. ${ }^{5)}$ on 2,010 cases, it was reported that the rate of detection of skin lesion in the lumbosacral region was $7.2 \%$ (144 cases). In addition to this, spinal pathological finding in US was recognized only in eight of 144 cases. In another study by Değirmenci et al. ${ }^{2}$ on 1000 newborns, it was reported that the rate of detection of skin lesion in the lumbosacral region was $5 \%^{3-5,122}$. In our study, the rate of detection of skin lesion at the midline was $28 \%$. We determined the high incidence was due to involvement of benign skin lesion such as Mongolian spot and salmon patch that can be located at the midline, but are not related to spinal dysraphism. On the middle line of skin lesions in our study, the detection rate was $28 \%$. When these two lesions are withdrawn, the rate of observed skin lesions (7.4\%) was close to the rates reflected in the literature. We excluded cases with spinal pathological findings in US from the study. Therefore, spinal pathology was not recognized in cases in which skin lesions were recognized. Mongolian spot is reported as the most common dermatological finding (15.2\%). For instance, in studies conducted in Iran (71.3\%), Taiwan (61.6\%), and Brazil, it was reported as the most frequent finding ${ }^{7,8,13}$. In studies conducted in our country, reported rates are $20.1 \%$ and $13.2 \%{ }^{3,4}$. Salmon patch $(5.42 \%)$ is reported as the second-most common skin lesion. Sacral dimple, epidermal sinus, and hair development in the lumbosacral region were other commonly observed skin lesions in our study, and no statistically meaningful relationship was found between dermatological findings and the length of CM.

Transducers are very important in routine ultrasound practices; therefore, we recommend transducers up to $15 \mathrm{MHz}$ which provides images at high frequencies for this examination. When the examined infant gets older than 6 months, difficulties are arising in the verification of acoustic window. Moreover, it is important to specify L5 vertebra on ultrasound image. It would be beneficial to reveal the angulation between L5 and S1 vertebra.

\section{CONCLUSION}

According to the findings of this study, gender is not an influencing factor for termination of the spinal cord, and in 
conjunction with the previous literature, in infants without a recognized spinal pathology, the spinal cord is detected below the vertebra L3. In our study, lower level of conus termination was determined to be upper margin of the vertebra L3 until the age of 4 months in healthy-appearing children without neurological symptoms, In our opinion, conus that ends at the level of vertebra L3 either in presence of a neurological sign or symptom or over age of 4 months must be considered as pathological. Tethered cord syndrome should be investigated in detail in conus levels below this level.

\section{CONFLICTS OF INTEREST}

No potential conflict of interest relevant to this article was reported.

\section{INFORMED CONSENT}

Informed consent was obtained from all individual participants included in this study.

\section{References}

1. Arthurs OJ, Thayyil S, Wade A, Chong WK, Sebire NJ, Taylor AM; Magnetic Resonance Imaging Autopsy Study Collaborative Group : Normal ascent of the conus medullaris: a post-mortem foetal MRI study. J Matern Fetal Neonatal Med $26: 697-702,2013$

2. Değirmenci $S$, Güven $F$, Celayir $A, K$ Iıç BD, Say $A$ : Lumbosakral orta hat cilt lezyonlu yenidoğanlarda spinal kord anomalileri Orijinal Araştırma. Türk Pediatri Arşivi 38 : 103-106, 2003

3. Ferahbas A, Utas S, Akcakus M, Gunes T, Mistik S: Prevalence of cutaneous findings in hospitalized neonates: a prospective observational study. Pediatr Dermatol 26 : 139-142, 2009

4. Gokdemir G, Erdogan HK, Köşlü A, Baksu B : Cutaneous lesions in Turkish neonates born in a teaching hospital. Indian J Dermatol Venereol Leprol $75: 638,2009$

5. Henriques JG, Pianetti $G$, Henriques KS, Costa P, Gusmão S : Minor skin lesions as markers of occult spinal dysraphisms--prospective study. Surg Neurol $63: 8-12,2005$

6. Hill CA, Gibson PJ : Ultrasound determination of the normal location of the conus medullaris in neonates. AJNR Am J Neuroradiol 16 : 469472, 1995

7. Monteagudo B, Labandeira J, León-Muiños E, Carballeira I, Cabanillas M, Suárez-Amor 0 : Frequency of birthmarks and transient skin lesions in newborns according to maternal factors (diseases, drugs, dietary supplements, and tobacco). Indian J Dermatol Venereol Leprol $77: 535$, 2011

8. Moosavi Z, Hosseini T : One-year survey of cutaneous lesions in 1000 consecutive Iranian newborns. Pediatr Dermatol 23 : 61-63, 2006

9. Perlitz Y, Izhaki I, Ben-Ami $M$ : Sonographic evaluation of the fetal conus medullaris at 20 to 24 weeks' gestation. Prenat Diagn 30 : 862-864, 2010

10. Rozzelle CJ, Reed GT, Kirkman JL, Shannon CN, Chern JJ, Wellons JC 3rd, et al. : Sonographic determination of normal Conus Medullaris level and ascent in early infancy. Childs Nerv Syst 30 : 655-658, 2014

11. Sahin F, Selçuki $M$, Ecin N, Zenciroğlu A, Unlü A, Yilmaz F, et al. : Level of conus medullaris in term and preterm neonates. Arch Dis Child Fetal Neonatal Ed 77 : F67-F69, 1997

12. Sarıkaya Solak S, Tükenmez Demirci G, Kıvanç Altunay I, Küçükünal A : The relationship of birthmarks observed in 1000 newborns with neonatal/maternal parameters: a prospective and cross-sectional study. Turkiye Klinikleri J Med Sci 33 : 1388-1394, 2013

13. Shih $\mathrm{IH}$, Lin JY, Chen $\mathrm{CH}$, Hong HS : A birthmark survey in 500 newborns: clinical observation in two northern Taiwan medical center nurseries. Chang Gung Med J 30 : 220-225, 2007

14. Vettivel $S$ : Vertebral level of termination of the spinal cord in human fetuses. J Anat 179 : 149-161, 1991

15. Warder DE : Tethered cord syndrome and occult spinal dysraphism. Neurosurg Focus 10 : e1, 2001

16. Warder DE, Oakes WJ : Tethered cord syndrome and the conus in a normal position. Neurosurgery $33:$ 374-378, 1993

17. Warder DE, Oakes WJ : Tethered cord syndrome: the low-lying and normally positioned conus. Neurosurg 34 : 597-600; discussion 600, 1994

18. Wilson DA, Prince JR : John Caffey award. MR Imaging determination of the location of the normal conus medullaris throughout childhood. AJR Am J Radiol 152 : 1029-1032, 1989

19. Yamada S, Zinke DE, Sanders D : Pathophysiology of "tethered cord syndrome". J Neurosurg $54:$ 494-503, 1981

20. Zalel Y, Lehavi O, Aizenstein O, Achiron R : Development of the fetal spinal cord: time of ascendance of the normal conus medullaris as detected bysonography. J Ultrasound Med 25 : 1397-1401, 2006 